\title{
Study on the Impact of Strain Rate and Loading Speed on Geogrid-Reinforced Soil
}

\author{
Mohammadehsan Zarringol ${ }^{1}$ \& Mohammadreza Zarringol $^{2}$ \\ ${ }^{1}$ Faculty of Science, Engineering and Technology, Swinburne University of Technology, Hawthorn, Australia \\ ${ }^{2}$ Geotechnical Engineering Department, University of Guilan, Rasht, Iran \\ Correspondence: Mohammadehsan Zarringol, Geotechnical Engineering Department, University of Guilan, Rasht, \\ Iran. Tel: 98-91-2106-7501. E-mail: Ehsan.zaringol@gmail.com
}

\author{
Received: December 6, $2016 \quad$ Accepted: January 17, $2017 \quad$ Online Published: March 30, 2017 \\ doi:10.5539/jsd.v10n2p238 URL: https://doi.org/10.5539/jsd.v10n2p238
}

\begin{abstract}
During the past decades, reinforced soil has normally been constructed by coarse grained soil. Recently, low quality and locally accessible materials have been successfully used in reinforced soil due to economic observations. Loading speed is one of the effective factors in soil-geosynthetic interaction. In order to determine the impact of this factor, we carried out a pullout test on the samples with dimensions of $30 \times 30 \times 17 \mathrm{~cm}$ under four strain rates of 0.75 , $1.25,1.75$ and $2.25 \mathrm{~mm} / \mathrm{min}$ and three vertical stress rates of 20,50 and $80 \mathrm{KN} / \mathrm{m}^{2}$. The results of this study indicated that the mobilization of geosynthetic strength in contact area depends on the amount of vertical stress. The increased vertical stress results in the increased shear strength in clay-geogrid contact area. Furthermore, the increased strain rate results in the reduced shear strength.
\end{abstract}

Keywords: reinforced soil, geosynthetic, strain rate, loading speed, clay

\section{Introduction}

Soft clay soils have low bearing capacity and tend to settle under the influence of external loads. In order to prevent excessive settlement, they must be improved before construction process. This paper aims to determine the impact of geo-synthetic coarse-grained reinforcement on bearing capacity of soft clay. The advantages of grain materials include good drainage, high friction resistance, and good stability against humidity and time (Elias, V., Barry, P. E., \& Christopher, R. 1997). Reinforced-soil structures are often constructed by coarse-grained materials because fine-grained soils have poor drainage and friction resistance and tend to change under the influence of humidity and time (Lin, H., \& Atluri, S. N. 2001). Normally, membranous and confinement impacts are considered in soil reinforcement. In membranous impact, foundation and soil move downward and reinforcement layers are gradually tensioned. To bear the load, the deformed reinforcement exerts a force upward. The reinforcement under tension needs a specific amount of settlement to mobilize membranous effect. Furthermore, the reinforcement must have sufficient length and stiffness. The upward force is developed at the conjunction of reinforcement and failure surface (Wang, Z., Jacobs, F., \& Ziegler, M. 2014; Ze, L., \& Yong, L. 2014). Patra et al (2006) conducted a series of studies on geo-grid reinforced sand with eccentric loading and reported that the increased layers of geo-grid resulted in the increased bearing capacity (Patra, C. R., Das, B. M., Bhoi, M., \& Shin, E. C. 2006). In 2001, Alawaji conducted a study on settlement and bearing capacity of geo-grid reinforced sand located on weak soil. He reinforced the sand using a geo-grid layer and found that the optimal depth of geo-grid placement for reaching the maximum bearing capacity was $10 \%$ of foundation diameter. This result was in line with the studies of other researchers such as Khing (Khing et al., 1993)

Alawaji conducted a series of studies to determine the impact of geo-grid diameter change on load-settlement behavior of samples. He reported that the increased diameter of geo-grid resulted in a significant reduction of settlement in equal capacities (Alawaji, H. A. 2001). Sharma et al. (2009) examined the foundations placed on geo-grid reinforced soil and found that the first layer of reinforcement must be close to foundation with an optimal depth range of $0.5 \mathrm{~B}-2 \mathrm{~B}$ in which $\mathrm{B}$ is the footing width. They also reported that the length of reinforcement must be between 2B and 8B (Sharma, R., Chen, Q., Abu-Farsakh, M., \& Yoon, S. 2009). Nazir and Sawwaf (2010) conducted a study on the behavior of rectangular foundation located on geo-grid reinforced sand. They reported that the increased soil density resulted in the increased impact of geo-grid layers on bearing capacity (El Sawwaf, M., \& Nazir, A. K. 2010). Basudhar et al. investigated the behavior of circular foundation located on geo-grid reinforced 
sand. They found that the increased number of geo- grid layers resulted in the increased bearing capacity. They also reported that the increased density of sand led to failure in higher settlements (Basudhar, P. K., Saha, S., \& Deb, K. 2007).

This paper aims to determine the impact of strain rate and loading speed on geogrid-reinforced soil. This is the first paper to conduct a comprehensive study on this subject.

\section{Materials and Methods}

\subsection{Shear Strength}

The shear strength between reinforcement and soil is provided by 1) the shear strength in the contact area between reinforcement and soil and 2) the shear strength between soils in open meshes of the geo-grid.

Equation 1 represents total direct shear strength $\left(F_{t}\right)$ (Sreekantiah, H. R., \& Unnikrishnan, N. 1992):

$$
\begin{gathered}
F_{t}= \\
\sigma_{n} A\left[\alpha _ { d s } \operatorname { t a n } \left(\delta+\left(1-\alpha_{d s}\right) \tan \phi\right.\right. \text { Alawaji conducted a study on settlement and bearing capacity of geo - } \\
\text { grid reinforced })]
\end{gathered}
$$

$\phi$ : Internal friction angle of soil in direct shear

$\delta$ : Apparent friction angle of shear surface of reinforcement and soil

$\alpha_{\mathrm{ds}}$ : The ratio of shear surface of reinforcement to total shear surface

$\sigma_{\mathrm{n}}$ : Vertical stress in shear surface and A: total shear surface

Many researchers have recognized bond coefficient as an important parameter in reinforced-soil design (Liu, C. N., Ho, Y. H., \& Huang, J. W. 2009; Wang, Z., \& Richwien, W. 2002; GHIASIAN, H., \& Jahannia, M. 2004). They have defined bond coefficient as the ratio of soil-soil contact area strength to soil-reinforcement contact area strength. In this definition, soil-soil contact surface strength is the direct shear strength of the soil, provided that shear surface is soil-reinforcement shear surface (Das, B. M., Cook, E. E., Shin, E. C., Yen, S. C., \& Puri, V. K. 1993).

If the bond coefficient is bigger than unit number, a powerful bond exists between soil and geo-grid and soil-reinforcement contact area strength is higher than soil-soil contact area strength. If it is smaller than 0.5 , there is a weak bond between soil and geo-grid (Jewell, R. A., \& Wroth, C. P. 1987).

\subsection{Bond Coefficient}

So far, many researchers have studied the friction behavior of soil-geo-grid contact area, with an emphasis on the parameters of humidity percentage, soil type and density, geometry, stiffness of geo-grid, and vertical stress (Sridharan, A., Murthy, B. S., Bindumadhava, \& Revanasiddappa, K. 1991). They have compared the friction angle mobilized in soil-geo-grid contact area with internal friction angle of soil and defined factor $\mathrm{C}_{\mathrm{i}}$ (effective bond coefficient) in the form of equation 2 :

$$
\mathrm{C}_{\mathrm{i}}=\frac{\mathrm{C}_{\mathrm{a}}+\sigma_{\mathrm{n}} \tan \delta_{\mathrm{a}}}{\mathrm{C}+\sigma_{\mathrm{n}} \tan \phi}
$$

$\mathrm{C}_{\mathrm{a}}$ : Bond between soil and geo-grid

$\delta_{\mathrm{a}}$ : Apparent friction angle of contact area

C: Soil bond

$\phi$ : Internal friction angle of soil

$\sigma_{\mathrm{n}}$ : Vertical stress

If the tested soil is sand, bond coefficient is simplified as follows:

$$
\mathrm{C}_{\mathrm{i}}=\frac{\tan \delta_{\mathrm{a}}}{\tan \phi}
$$

Bond coefficient of the reinforcement depends on geo-synthetic surface, bearing capacity of transverse members, bearing capacity of surrounding soil, type of soil, and the length of buried sample. In soil-reinforcement direct shear bond mechanism, the shear strength of contact area is a combination of soil-soil direct shear strength and soil-reinforcement direct shear strength. If bond coefficient is smaller than 0.5 , a weak bond exists between soil and geo-grid. If it is bigger than 1, a strong bond exists between soil and geo-grid. 


\subsection{Materials}

We carried out the tests using kaolinite clay. The Clay was a mixture of three types of uniform with grain sizes of 0.7-1.2, 1-2 and 2-4 mm. Figure 1 illustrates the information of clay mixture based on ASTM standards. Figure 2 illustrates the compaction curves. Based on unified soil classification system (USCS), clay is classified in CL group (clay with low plastic property) and sand is classified in SW group (finely grained sand). The tests were carried out using a large direct shear device with some modifications for connecting the geo-synthetics to lower shear box by clamp (according to D5321 ASTM) (Unnikrishnan, N., Rajagopal, K., \& Krishnaswamy, N. R. 2002). Tables 1 contains the properties of geogrid used for the purpose of this study.

Table 1. Properties of geogrid used in this study (GEO_GRID_1, CE121)

\begin{tabular}{rr} 
Properties & Value \\
\hline Liquid limit (\%) & 26.5 \\
Plastic limit (\%) & 4.5 \\
Plasticity index (\%) & 22 \\
Optimum moisture (\%) & 17 \\
Maximum dry density $(\mathrm{g} / \mathrm{cm} 3)$ & 1.78 \\
Cohesion $(\mathrm{kPa})$ & 11.7 \\
Internal friction angle & 22.5 \\
Weight $(\mathrm{kg} / \mathrm{m} 2)$ & 0.73 \\
Thickness $(\mathrm{mm})$ & 2.2 \\
Aperture shape & Square \\
Color & Black \\
Tensile strength $(\mathrm{KN} / \mathrm{m})$ & 8.2 \\
Type & HDPE \\
Aperture size $(\mathrm{mm})$ & $8 \times 8$ \\
&
\end{tabular}

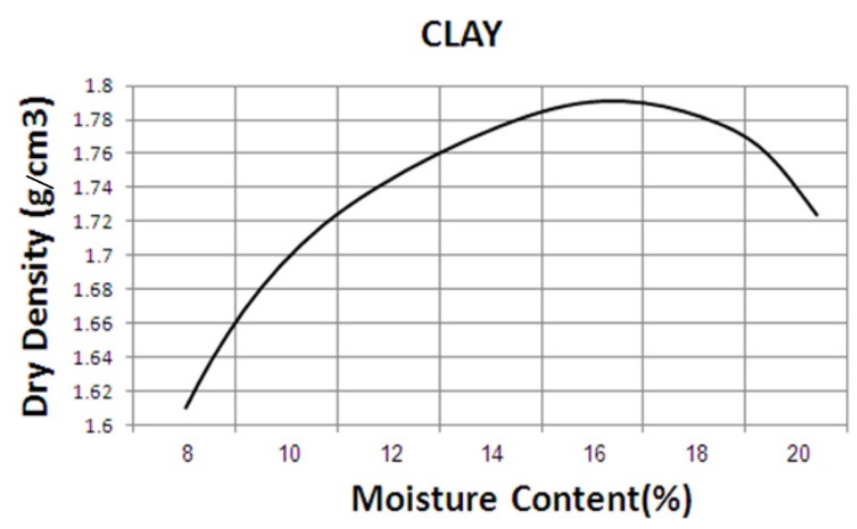

Figure 1. Clay compaction curve 
0.7-1.2 m

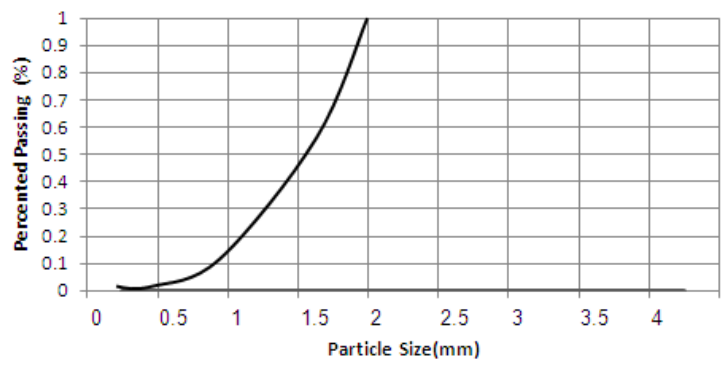

2.0-4.0 m

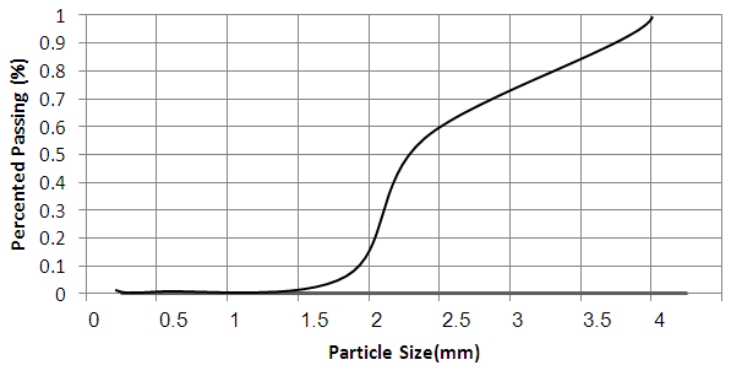

1.0-2.0 m

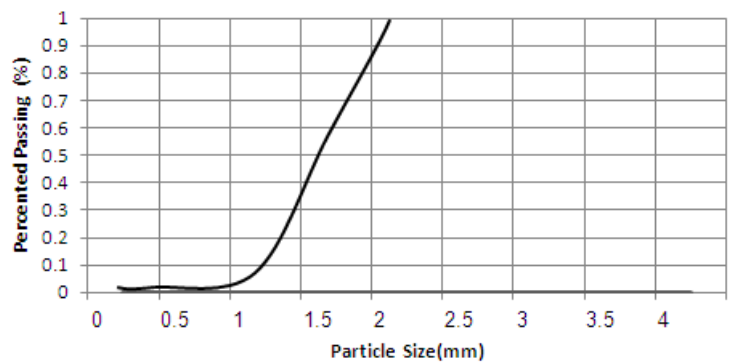

0.7-4.0 m

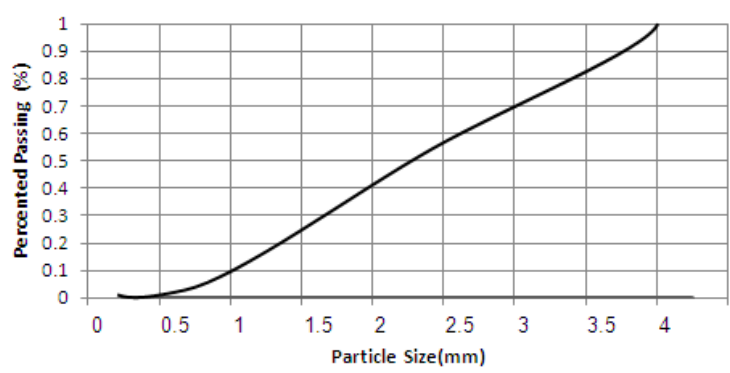

Figure 2. Clay gradation curve

\subsection{Test Method}

We first poured the soil into the lower part of the shear box in three layers with optimum moisture content. Each layer was compacted by a rubber mallet with 30 blows (10 blows at the center and 5 blows at each side) so that its dry density reached the maximum dry density obtained from standard proctor test. In all pullout tests, the clay samples compacted in the shear box had equal optimum moisture and compaction. We fixed the geogrid sample by the clamp with a length-to-width ratio of 2 in a fully horizontal manner so that the distance between the end of geogrid sample and shear box reached $7.5 \mathrm{~m}$. Next, we filled the upper part of the shear box with the compacted soil (Mohiuddin, A. 2003; Biswas, A., Ansari, M. A., Dash, S. K., \& Krishna, A. M. 2015).

After placing the upper plate of the shear box, we applied a vertical load of 20,50 and $80 \mathrm{KN} / \mathrm{m}^{2}$. Two gauges were attached to the device to measure the displacement and horizontal force applied to geogrid sample. Next, we started the horizontal displacement generator with the speeds of $0.75,1.25,1.75$ and $2.25 \mathrm{~mm} / \mathrm{min}$. For each $0.5 \mathrm{~mm}$ of horizontal displacement, we read the dynamometer to determine the tensile horizontal force. The test was continued until the horizontal displacement of $2 \mathrm{~cm}$. This amount of displacement was equal to initial displacement of geogrid sample (close to the clamp). We determined the pullout force based on the figures shown on the gauge and the width of geogrid sample.

In order to measure the change of reinforcement length, we marked the longitudinal coordinates by inserting needles into the soil at the specified points. At the end of test, we measured the new coordinates based on the marked needles and determined the tensile displacement of geogrid. This method was used instead of strain gauge method (Bhat, S., \& Thomas, J. 2015).

\section{Results and Discussion}

Horizontal displacement rate is an effective factor in soil-geogrid contact area. In the following paragraphs, we present pullout test results for clay samples reinforced by CE121 geogrid with longitudinal tensile strength of 7.68 $\mathrm{KN} / \mathrm{m}$ under normal stress of 20,50 and $80 \mathrm{Kpa}$ and horizontal displacement rates of $0.75,1.25,1.75$ and 2.25 $\mathrm{mm} / \mathrm{min}$. Based on the Figure 3, a slight increase of shear displacement (approximately $1 \mathrm{~mm}$ ) has led to a severe increase in pullout force. Moreover, the increased shear displacement has led to the reduced shear stress. The noticeable point is that the pullout force has incrementally increased after the severe increase in shear force in the initial steps of the test. This behavior is almost in line with Zhang's (Zhang et al,. 2016) pullout tests using geogrid reinforcement.

The comparison of the curves shown in figures 2, 3 and 4 for normal stresses of 20,50 and 80 Kpa indicates that the highest pullout-displacement curve of the geogrid under normal stresses of 20, 50 and $80 \mathrm{Kpa}$ belongs to strain rate of $0.75 \mathrm{~mm} / \mathrm{min}$. As shown in the diagrams, the higher the strain rate, the less the difference between the results of 
clay-geogrid shear strength.

$0.75 \mathrm{~mm} / \mathrm{min}$

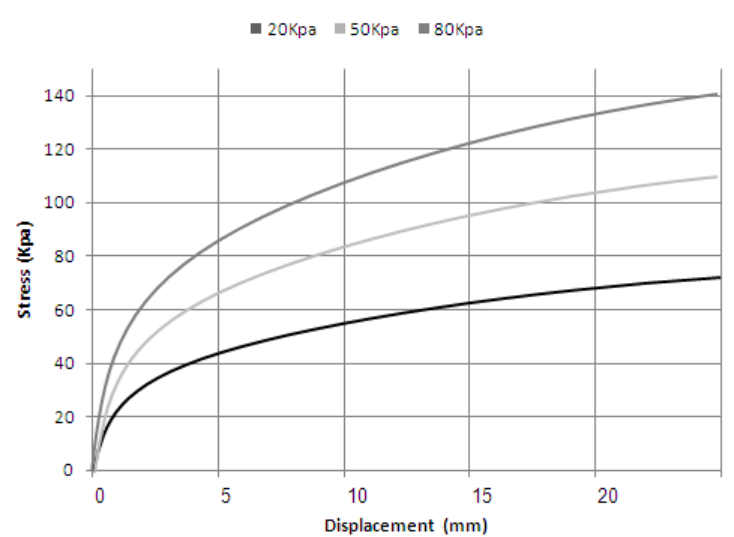

$1.75 \mathrm{~mm} / \mathrm{min}$

- $20 \mathrm{Kpa}=50 \mathrm{Kpa}=80 \mathrm{Kpa}$

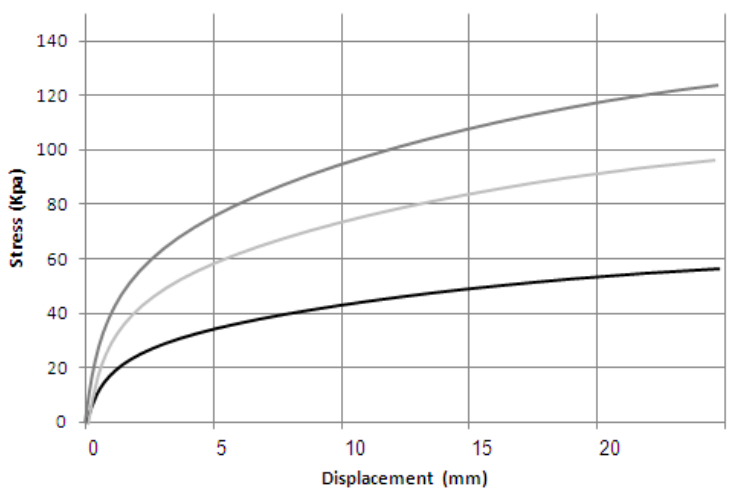

$1.25 \mathrm{~mm} / \mathrm{min}$

- $20 \mathrm{Kpa}=50 \mathrm{Kpa}=80 \mathrm{Kpa}$

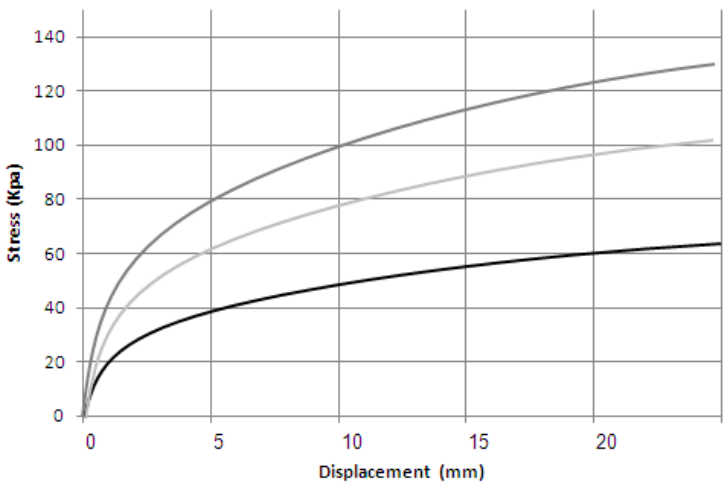

$2.25 \mathrm{~mm} / \mathrm{min}$

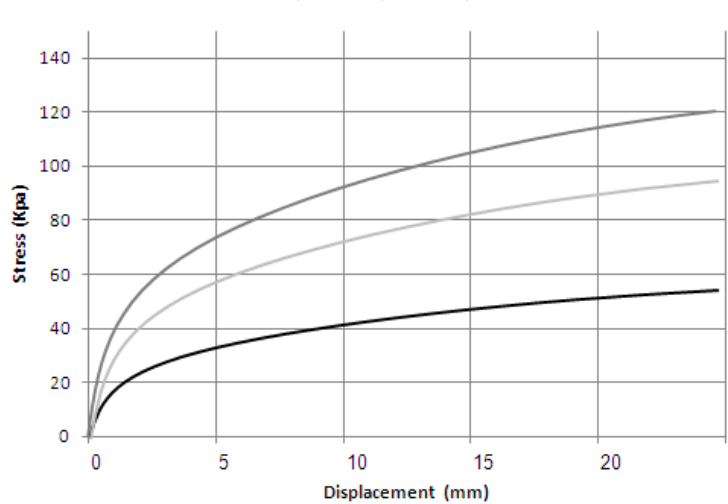

Figure 3. Geogrid pullout force-displacement diagram

Figure 4 illustrates the failure envelopes of clay-geogrid samples obtained from pullout tests. The apparent cohesion coefficient $\left(\mathrm{C}_{\mathrm{a}}\right)$ has decreased from 54.05 to $44.36 \mathrm{KN} / \mathrm{m}$ and the apparent friction angle $(\delta \mathrm{a})$ has decreased from 47.12 to 41.47 (Figure 4 ).

\section{$0.75 \mathrm{~mm} / \mathrm{min}, \mathrm{Ca}=54.05, \delta a=47.12$}

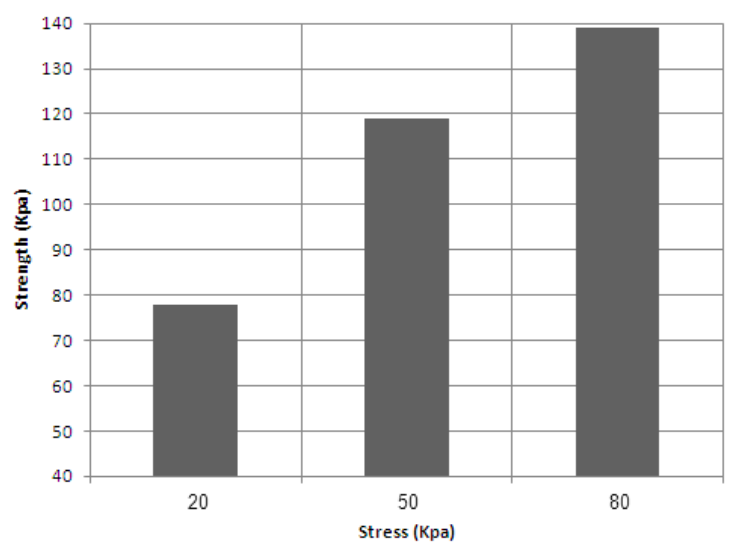

$1.25 \mathrm{~mm} / \mathrm{min}, \mathrm{Ca}=49.03, \delta a=44.43$

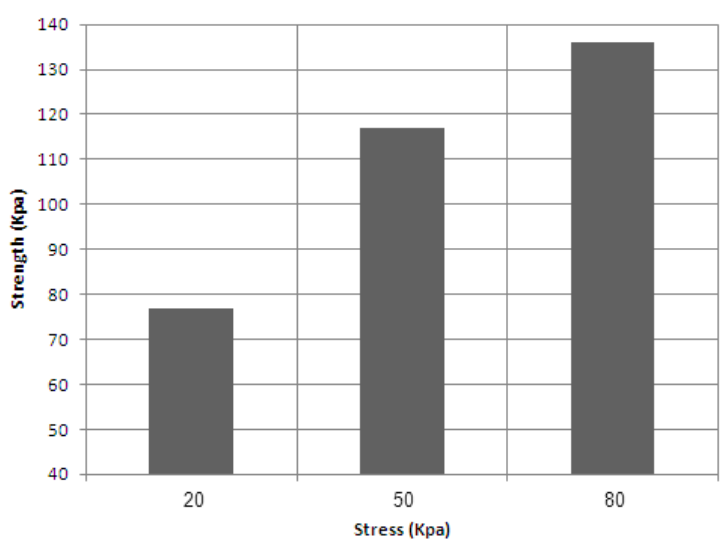


$1.75 \mathrm{~mm} / \mathrm{min}, \mathrm{Ca}=46.23, \delta a=42.64$

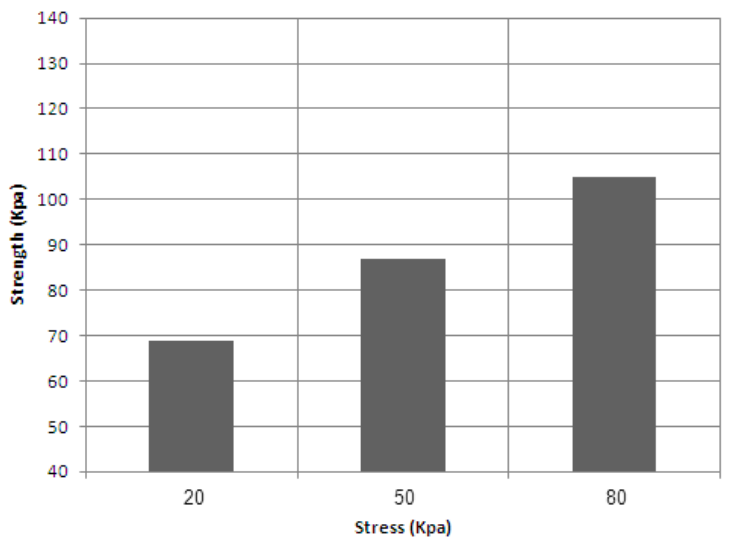

$2.25 \mathrm{~mm} / \mathrm{min}, \mathrm{Ca}=44.36, \delta a=41.47$

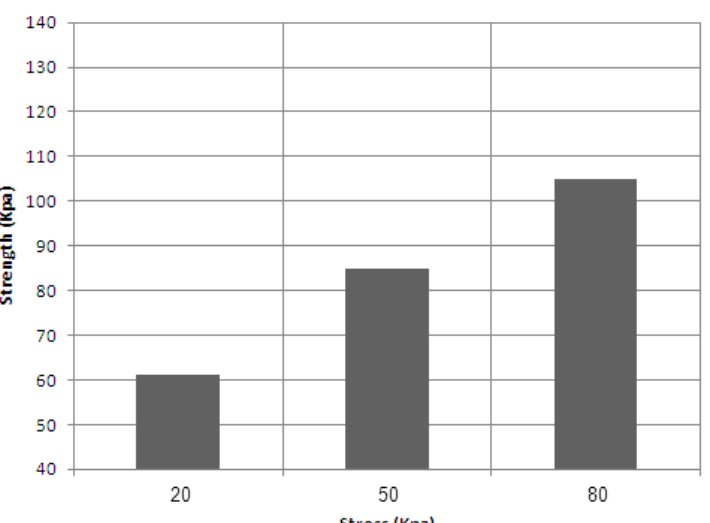

Figure 4. Maximum pullout force and normal stress of geogrid

In the pullout force-displacement diagram, the highest shear strength is obtained in the strain rate of $0.75 \mathrm{~mm} / \mathrm{min}$. The increased strain rate results in the reduced shear strength of clay-geogrid sample. Furthermore, the increased normal stress in contact area results in the increased pullout shear strength.

Demir reported that the increased normal stress led to the increased shear stress (Demir, A., Yildiz, A., Laman, M., \& Ornek, M. 2014) and the increased geosynthetic tensile strength led to the increased apparent friction angle. These results are in line with the results of the present study. Figure 5 illustrates pullout force-strain diagrams and shows that the increased strain rate up to the value of 0.01 has led to a severe increase in pullout force. In higher strain rates, the increasing trend significantly declines.

$0.75 \mathrm{~mm} / \mathrm{min}$

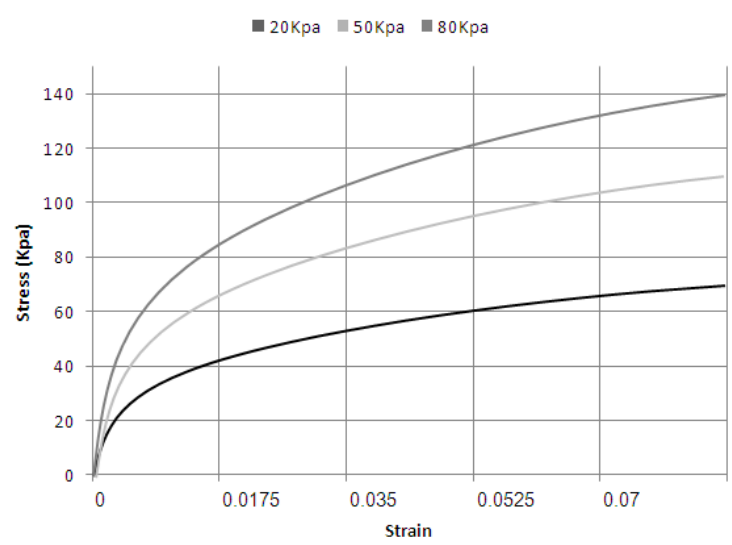

$1.75 \mathrm{~mm} / \mathrm{min}$

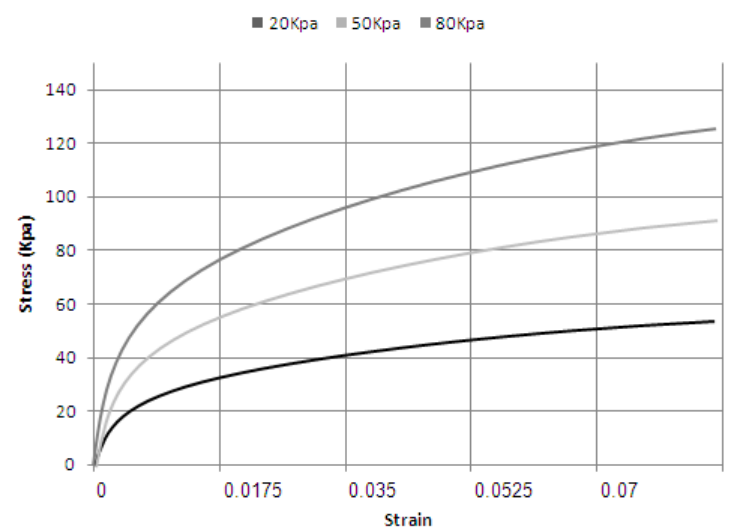

$1.25 \mathrm{~mm} / \mathrm{min}$

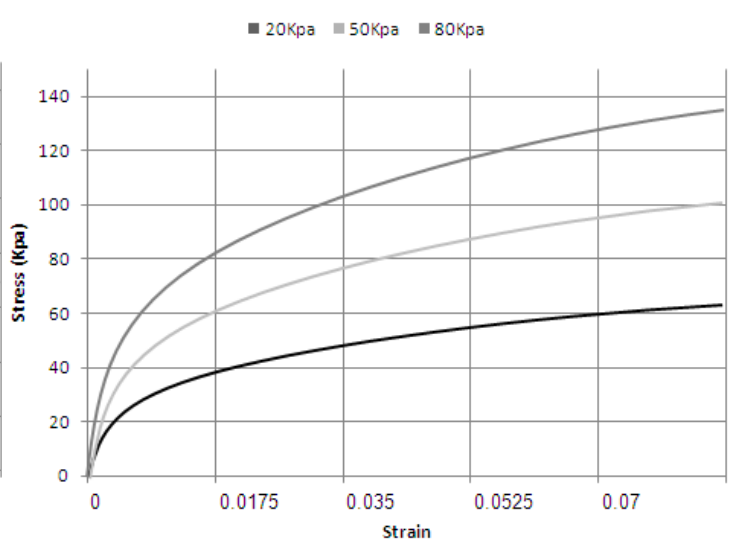

$2.25 \mathrm{~mm} / \mathrm{min}$

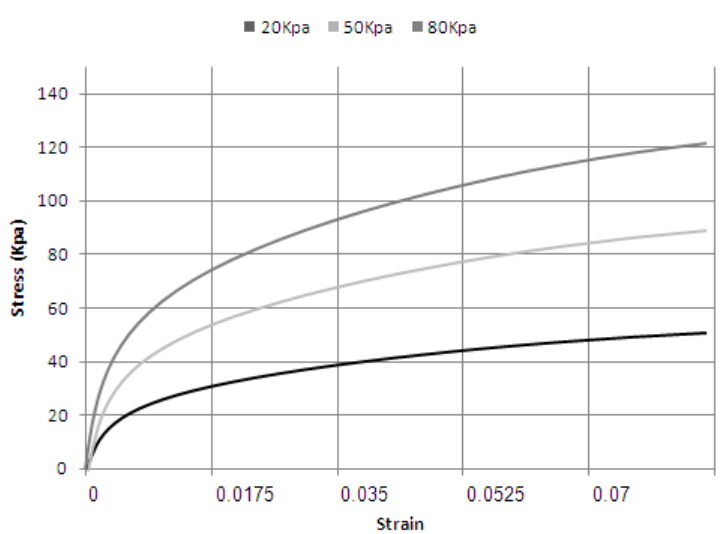

Figure 5. Pullout force-strain diagram 
Figures 6-8 contain the strain rates, normal stresses, maximum pullout stress, $\mathrm{F}_{\mathrm{T}}$ and the corresponding strain rates $\left(\varepsilon_{i}\right)$.

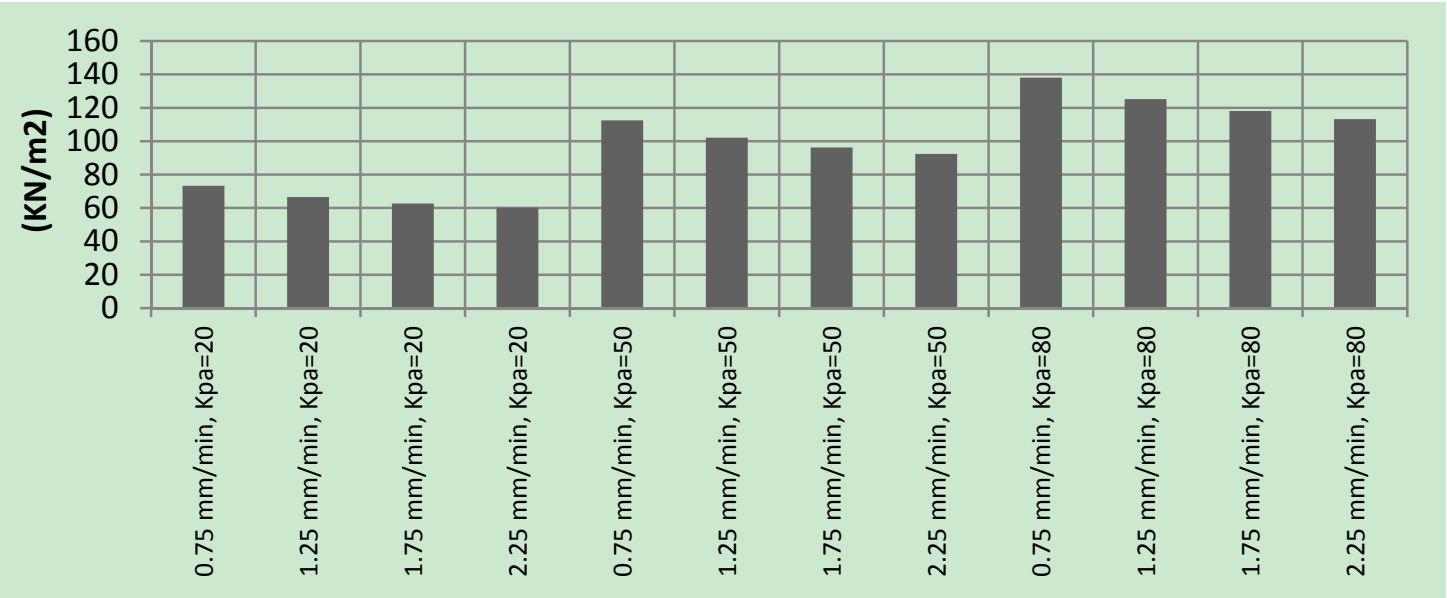

Figure 6. Maximum pullout stress

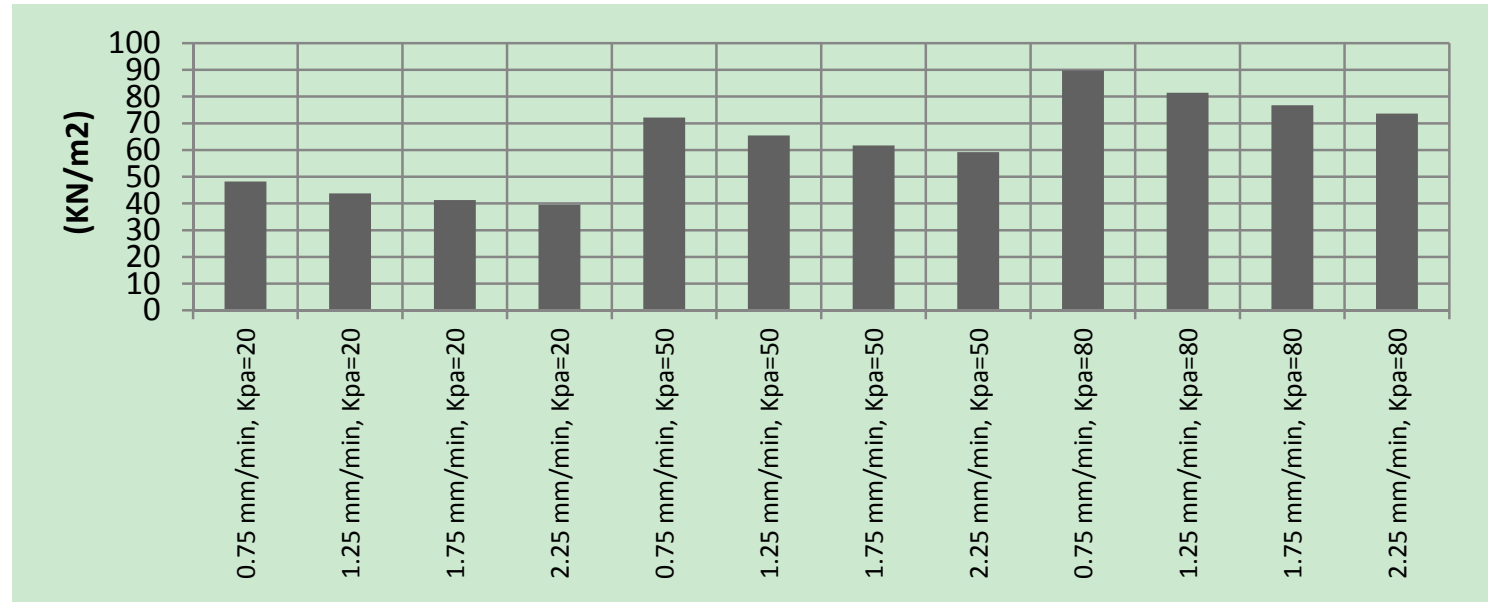

Figure 7. $F_{t}$

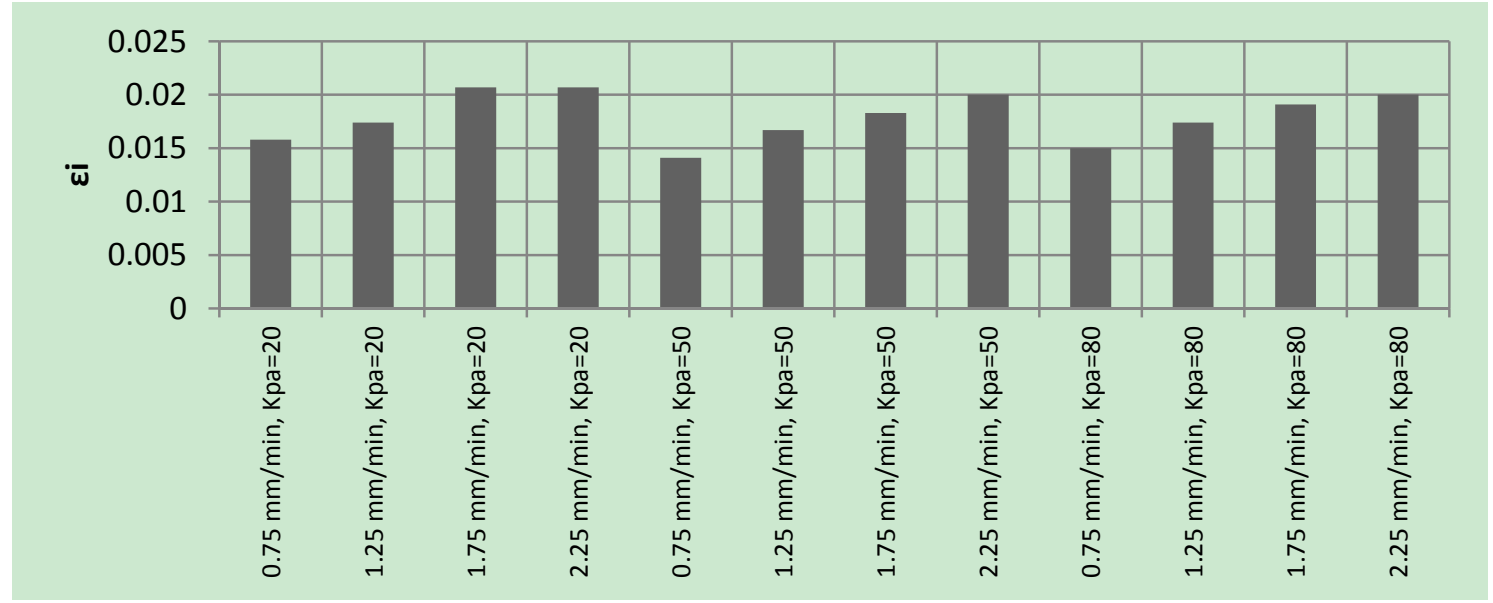

Figure 8. $\varepsilon_{\mathrm{i}}$ 
We obtained $\mathrm{C}_{\mathrm{a}}$ and $\boldsymbol{\delta}_{\mathrm{a}}$ from normal stress-pullout force diagrams and determined $\mathrm{f}_{\max }$ by using equation 1. Figure 9 illustrates the changes in interaction coefficient based on optimum moisture content which indicates the increased normal stress has led to the increased interaction coefficient in all strain rates. It should be noted that interaction coefficient is inversely associated with strain rate.

The increased normal stress has led to the increased interaction coefficient, which indicates that CE121 geogrid offers a relatively good cohesion. Under real conditions, the shear failure would exceed the lowest shear strength, in which case the interaction coefficient cannot be bigger than 1. In effect, an interaction coefficient of bigger than 1 means that soil-geogrid contact area can provide the minimum shear strength.

$0.75 \mathrm{~mm} / \mathrm{min}$

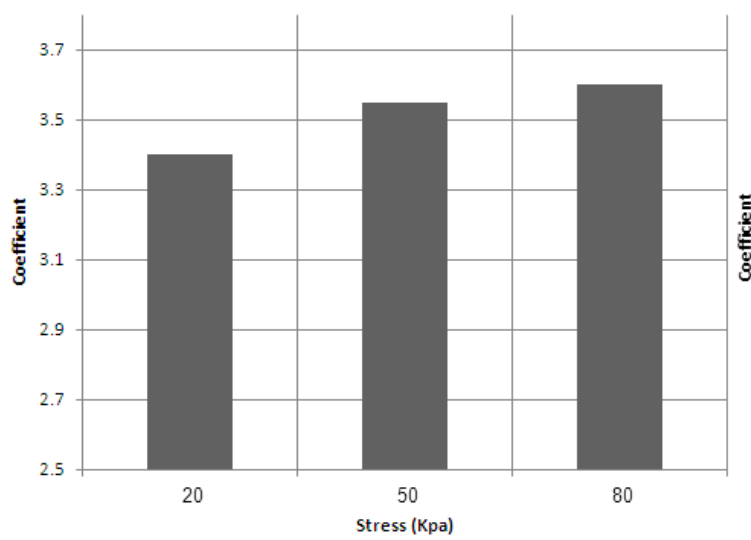

$1.75 \mathrm{~mm} / \mathrm{min}$

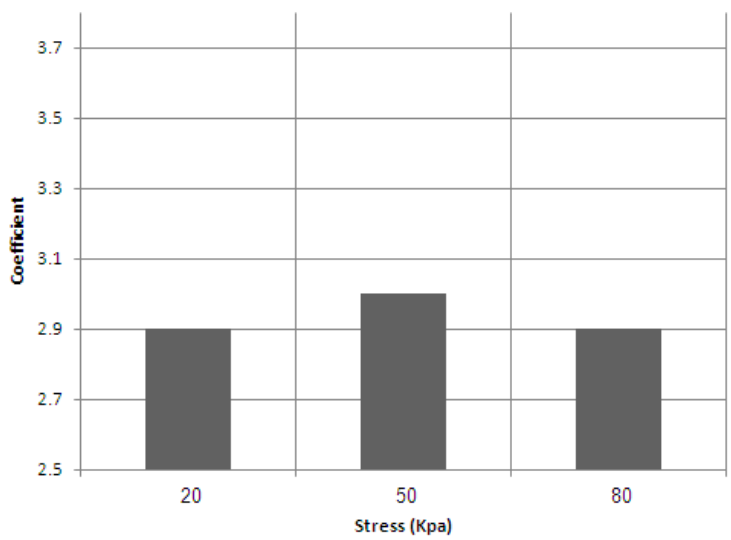

\section{$1.25 \mathrm{~mm} / \mathrm{min}$}

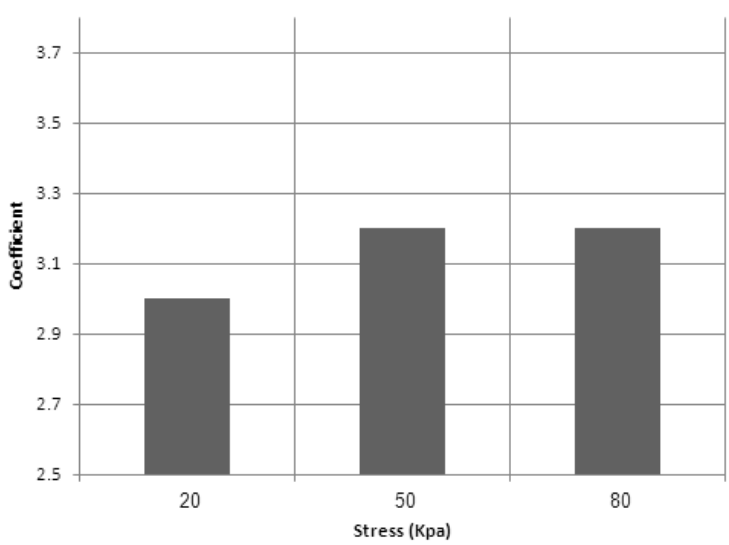

$2.25 \mathrm{~mm} / \mathrm{min}$

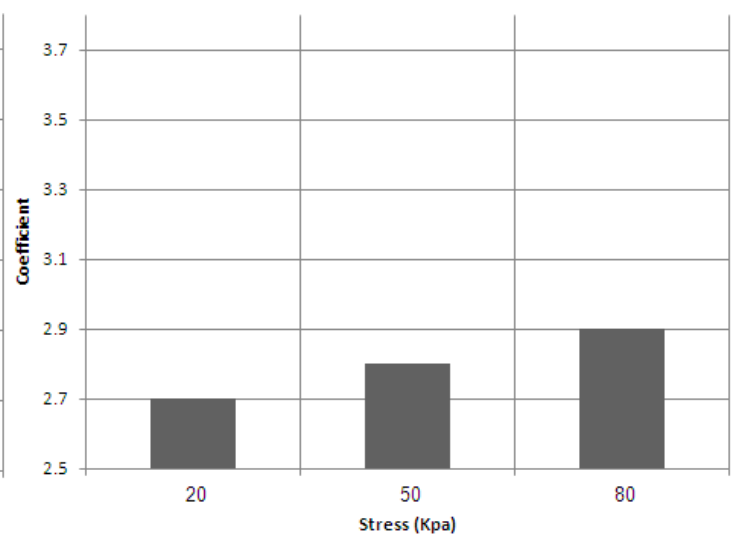

Figure 9. Interaction coefficient-normal stress diagram based on optimum moisture content

In this test, the sample has optimal moisture and maximum dry density. Figure 10 illustrates the deformations in different points of CE121 geogrid with the distance of $2.5 \mathrm{~cm}$ from the edge of shear box after completion of the test. Total displacement in the beginning of geogrid is $20 \mathrm{~mm}$ and due to elasticity of geogrid, the deformations along the length of geogrid has declined in a nonlinear manner. Consequently, there is a nonlinear distribution of shear stress along the length of geogrid. 


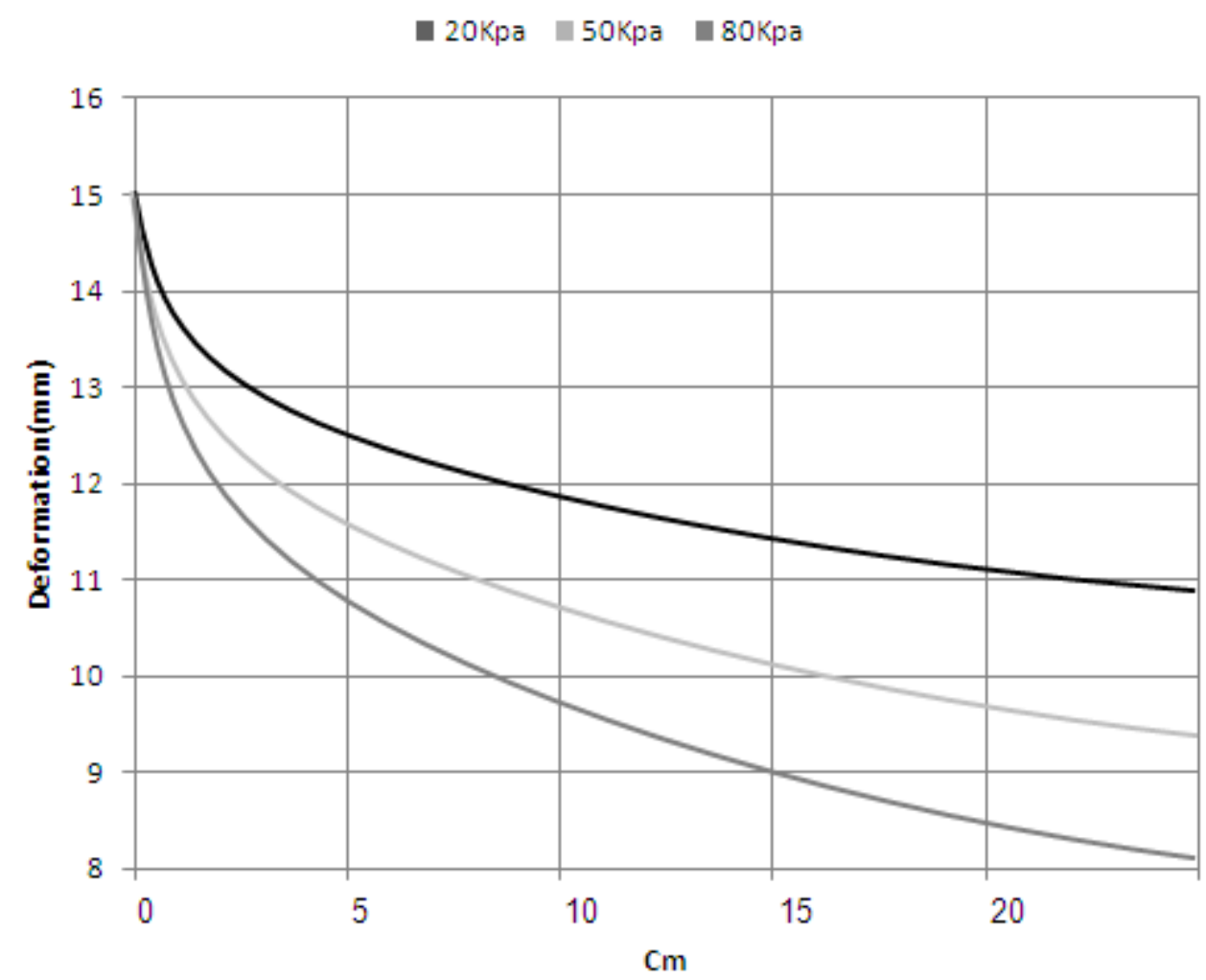

Figure 10. Deformation in different points of CE121 geogrid along the length of sample in comparison with the edge of shear box in clay sample

\section{Conclusion}

In this paper, we studied the impact of strain rate and loading speed on geogrid-reinforced soils. Loading speed is one of the effective factors in soil-geosynthetics interaction. In order to determine the impact of this factor, we carried out a pullout test on the samples with dimensions of $30 \times 30 \times 17 \mathrm{~cm}$ under four strain rates of $0.75,1.25,1.75$ and 2.25 $\mathrm{mm} / \mathrm{min}$ and three vertical stress rates of 20,50 and $80 \mathrm{~kg}$. The results of this study confirmed that:

Clay-geogrid sample showed a fully hardening behavior and there was no softening behavior during the test.

Mobilization of geogrid strength in contact area depends on the amount of vertical stress. In higher vertical stresses, geogrid shows a higher strength.

Shear strength is inversely associated with strain rate. The highest shear strength belongs to strain rate of 0.75 $\mathrm{mm} / \mathrm{min}$ and the lowest shear strength belongs to the strain rate of $2.25 \mathrm{~mm} / \mathrm{min}$.

The diagrams for different points of the geogrid samples indicate that the displacement of the points at which pullout force is applied (close to the clamp) is equal to initial displacement $(20 \mathrm{~mm})$. As we get away from the clamp, the deformation declines in all normal stresses. Moreover, the curves indicate that the increased normal stress results in the increased deformation along the length of geogrid sample.

\section{References}

Alawaji, H. A. (2001). Settlement and bearing capacity of geogrid-reinforced sand over collapsible soil. Geotextiles and Geomembranes, 19(2), 75-88. https://doi.org/10.1016/S0266-1144(01)00002-4

Basudhar, P. K., Saha, S., \& Deb, K. (2007). Circular footings resting on geotextile-reinforced sand bed. Geotextiles and Geomembranes, 25(6), 377-384. https://doi.org/10.1016/j.geotexmem.2006.09.003

Bhat, S., \& Thomas, J. (2015). Use of Polymer Geogrid Composite to support rail track over weak saturated clay subgrade-a case study.

Biswas, A., Ansari, M. A., Dash, S. K., \& Krishna, A. M. (2015). Behavior of geogrid reinforced foundation systems supported on clay subgrades of different strengths. International Journal of Geosynthetics and Ground Engineering, 1(3), 1-10. https://doi.org/10.1007/s40891-015-0023-5 
Das, B. M., Cook, E. E., Shin, E. C., Yen, S. C., \& Puri, V. K. (1993). Bearing capacity of strip foundation on geogrid-reinforced clay.

Demir, A., Yildiz, A., Laman, M., \& Ornek, M. (2014). Experimental and numerical analyses of circular footing on geogrid-reinforced granular fill underlain by soft clay. Acta Geotechnica, 9(4), 711-723. https://doi.org/10.1007/s11440-013-0207-x

El Sawwaf, M., \& Nazir, A. K. (2010). Behavior of repeatedly loaded rectangular footings resting on reinforced sand. Alexandria Engineering Journal, 49(4), 349-356. https://doi.org/10.1016/j.aej.2010.07.002

Elias, V., Barry, P. E., \& Christopher, R. (1997). Mechanically Stabilized Earth Walls and Reinforced Soil Slopes Design and Construction Guidelines: FHWA Demonstration Project 82, Reinforced Soil Structures WSEW and RSS. US Department of Transportation, Federal Highway Administration.

GHIASIAN, H., \& Jahannia, M. (2004). Influence of encapsulated geogrid-sand system on bearing capacity and settlement characteristics of reinforced clay.

Jewell, R. A., \& Wroth, C. P. (1987). Direct shear tests on reinforced sand. Geotechnique, 37(1), 53-68. https://doi.org/10.1680/geot.1987.37.1.53

Khing, K. H., Das, B. M., Puri, V. K., Cook, E. E., \& Yen, S. C. (1993). The bearing capacity of a strip foundation on geogrid-reinforced sand. Geotextiles and Geomembranes, 12(4), 351-361. https://doi.org/10.1016/0266-1144(93)90009-D

Lin, H., \& Atluri, S. N. (2001). The meshless local Petrov-Galerkin (MLPG) method for solving incompressible Navier-Stokes equations. CMES- Computer Modeling in Engineering and Sciences, 2(2), 117-142.

Liu, C. N., Ho, Y. H., \& Huang, J. W. (2009). Large scale direct shear tests of soil/PET-yarn geogrid interfaces. Geotextiles and Geomembranes, 27(1), 19-30. https://doi.org/10.1016/j.geotexmem.2008.03.002

Mohiuddin, A. (2003). Analysis of Laboratory and Field Pull-Out Tests of Geosynhthetics in Clayey Soils (Doctoral dissertation, Faculty of the Louisiana State University and Agricultural and Mechanical College in partial fulfillment of the requirements for the degree of Master of Science in Civil Engineering in The Department of Civil and Environmental Engineering by Ather Mohiuddin BE, Osmania University).

Patra, C. R., Das, B. M., Bhoi, M., \& Shin, E. C. (2006). Eccentrically loaded strip foundation on geogrid$\begin{array}{lllll}\text { reinforced sand. Geotextiles and } & \text { Geomembranes, 24(4), }\end{array}$ https://doi.org/10.1016/j.geotexmem.2005.12.001

Sharma, R., Chen, Q., Abu-Farsakh, M., \& Yoon, S. (2009). Analytical modeling of geogrid reinforced soil $\begin{array}{llll}\text { foundation. } & \text { Geotextiles }\end{array}$ https://doi.org/10.1016/j.geotexmem.2008.07.002

Sreekantiah, H. R., \& Unnikrishnan, N. (1992). Behaviour of geotextile under pullout. In Proc. of the Indian Geotechnical Conference, Calcutta (pp. 215-228).

Sridharan, A., Murthy, B. S., Bindumadhava, \& Revanasiddappa, K. (1991). Technique for using fine- grained soil in reinforced earth. Journal of geotechnical engineering, 117(8), 1174-1190. https://doi.org/10.1061/(ASCE)0733-9410(1991)117:8(1174)

Unnikrishnan, N., Rajagopal, K., \& Krishnaswamy, N. R. (2002). Behaviour of reinforced clay under monotonic and cyclic loading. Geotextiles and Geomembranes, 20(2), 117-133. https://doi.org/10.1016/S0266-1144(02)00003-1

Wang, Z., \& Richwien, W. (2002). A study of soil-reinforcement interface friction. Journal of Geotechnical and Geoenvironmental Engineering, 128(1), 92-94. https://doi.org/10.1061/(ASCE)1090-0241(2002)128:1(92)

Wang, Z., Jacobs, F., \& Ziegler, M. (2014). Visualization of load transfer behaviour between geogrid and sand $\begin{array}{llll}\text { using } & \text { 2D. Geotextiles and Geomembranes, } & 42(2), & 83-90 .\end{array}$ https://doi.org/10.1016/j.geotexmem.2014.01.001

Ze, L., \& Yong, L. (2014). Test Study on the Interface Friction Characteristics of Coal Gangue-Geogrid-Sand Layered System. Industrial Construction, 4, 22.

Zhang, C., Jiang, G., Liu, X., \& Buzzi, O. (2016). Arching in geogrid-reinforced pile-supported embankments over silty clay of medium compressibility: Field data and analytical solution. Computers and Geotechnics, 77, 11-25. https://doi.org/10.1016/j.compgeo.2016.03.007 


\section{Copyrights}

Copyright for this article is retained by the author(s), with first publication rights granted to the journal.

This is an open-access article distributed under the terms and conditions of the Creative Commons Attribution license (http://creativecommons.org/licenses/by/4.0/). 